\title{
ALGORITHMIC ECONOMY: A BIMODAL TRANSFORMATION IN U.S. BANKING
}

\author{
Jennifer Callen-Naviglia, Robert Morris University,jlcst421@mail.rmu.edu \\ Rana Alabdan, Robert Morris University, riast150@mail.rmu.edu
}

\begin{abstract}
Information technology has become an indispensable part of the U.S. banking industry. The industries commitment to evolving advantageous technology is evident in the growing financial commitment to distributed ledger or "blockchain" technology. The advancing technology is transforming the configuration of the U.S. banking industry model established with the passing of the Federal Reserve Act in 1913. The present paper investigates the literature to provide an understanding of the transformation of the U.S. banking industry created by advancing technology.
\end{abstract}

Keywords: Distributed Ledger Technology, Blockchain Technology, Algorithms, Bitcoin, Theory of Transformation, Theory of Transformation Pressure, Bimodal Transformation

\section{INTRODUCTION}

Technological advancements within the United States banking and financial industry are prevalent with the growing popularity of on-line banking, mobile check deposits, and development of digital currencies. The commitment by financial institutions to advance technical development within the financial realm is demonstrated by the January 2016 announcement by PNC Financial Services Group, Inc., parent company to PNC Bank, of its multiparty investment in Digital Assets Holdings LLC. Digital Asset Holdings LLC, is a New York based start-up focused on the development of distributed ledger technology specifically for the financial services industries (PNC Bank, January 2016). Distributed ledger technology is based on blockchain technology which supports the Bitcoin platform (PNC Bank; The Economist; PR Newswire Association LLC). Approximately, 13 financial institutions have invested a combined \$50 million into Digital Asset Holdings LLC as of January 2016. Investors include reputable global financial institutions such as, Citi; PNC Financial Group; J.P. Morgan; and Deutsche Borse Group. According to Blythe Masters, CEO of Digital Asset Holdings LLC, "These investments represent a tremendous endorsement of Digital Asset from banks, exchanges, settlement and clearing firms, central securities depositories, and market infrastructure and professional services providers" (PNC Bank, 2016).

PNC Financial Services released a statement on February 3, 2016 which explained the corporation's interest in distributed ledger technology. Per PNC, “...distributed ledger helps to provide transparency for transactions. The ability to have a globally available, verifiable and high-integrity ledger or journal provides anyone wishing to provide trusted third party services - major financial services firms, for example - with the ability to do so openly and robustly".

In an interview with Daniel Pavlick, CIO for PNC Corporate \& Institutional Banking, Mr. Pavlick states distributed ledger technology is making a central authority, for example the Federal Reserve, obsolete. Per Mr. Pavlick "distributed ledgers settle transactions faster because central authority, the FED, takes time to communicate - for information to travel from one banking facility to another". Mr. Pavlick stated the key to success for the banking industry is to 'derisk' and speed up transactions. Risk is created with lack of information comments Pavlick, "for example Bank 1 doesn't know what Bank 2 is doing putting the transaction at risk therefore speed helps reduce risk". So what would happen if no central authority existed? According to Mr. Pavlick, each banking entity using the distributed ledger technology would have its own 'node'. Each 'node' would provide a traceable path for all transactions. In addition, the transactions would be signed, verified, and irreversible. As noted by Mr. Pavlick having an accurate and verifiable history of transactions is key to gaining regulatory approval. Distributed ledger technology provides the essential chronological timeline of all transactions. 


\section{Issues in Information Systems \\ Volume 17, Issue II, pp. 9-16, 2016}

Another example of the imminent transformation, within U.S. banking through distributed ledger technology, occurred in April 2016 with the successful blockchain test involving "... single-named credit default swaps (CDS) among four big banks: Bank of America, Merrill Lynch, Citi, Credit Suisse, and JP Morgan" (Geuss, 2016, $1^{\text {st }}$ paragraph). A CDS, as defined by Geuss (2016), is debt sold from one bank to another "... with the understanding that if the debt holder defaults...the buyer bank will be compensated by the seller bank" (2 ${ }^{\text {nd }}$ paragraph). As Geuss (2016) notes, CDSs played a role in the 2008 financial crisis. Previously, CDSs were unregulated and essentially ignored by regulators. Since the 2008 financial crisis, the U.S. Treasury Department has sought to improve oversight on CDS transactions. The distributed ledger technology theoretically adds the desired transparency in that as Geuss (2016) notes, "... on a blockchain ledger peer-to-peer transaction can be monitored by every entity that's party to the ledger..." ( $3^{\text {rd }}$ paragraph).

A third and final example of the emerging importance of distributed ledger technology and its role in the transformation of the U.S. banking industry is highlighted by Federal Reserve Bank Governor Lael Brainard's April 14, 2016 speech in which he observed that, the key advantage of the distributed ledger technology is its ability to provide a credible way to transfer an asset without the need for trust in intermediaries or counterparts, much like a physical cash transaction" (10 $10^{\text {th }}$ paragraph). In addition, Governor Brainard (2016) notes the adoption of distributed ledger technology will assist in achieving greater efficiency by reducing time and risk in clearinghouse transfers and settlements. As pointed out previously by PNC's CIO for Corporate and Institutional Banking, Daniel Pavlick, banking institutions are interested in speeding up transactions which in turn reduce transactional risk. Table 1 highlights the three most appealing characteristics of distributed ledger technology as stated by Governor Brainard (2016).

Table 1

\begin{tabular}{|l|l|}
\hline \multicolumn{1}{|c|}{ Characteristic } & \multicolumn{1}{c|}{ Definition } \\
\hline Peer-to-peer networking and distributed data storage & $\begin{array}{l}\text { Multiple copies of a single ledger across all parties in } \\
\text { the system so that all parties have a shared history of } \\
\text { all transactions in the system in real time. }\end{array}$ \\
\hline Cryptography & $\begin{array}{l}\text { Examples are hashes and digital signatures. Provides a } \\
\text { secure manner to initiate a transaction that verifies } \\
\text { ownership and availability of funds or assets. }\end{array}$ \\
\hline Consensus algorithms & $\begin{array}{l}\text { Provides the procedure for the transactions to be } \\
\text { confirmed and validity on the single ledger. }\end{array}$ \\
\hline
\end{tabular}

Despite the growing interest in distributed ledger technology or blockchain, the Bitcoin platform continues to be ignored by U.S. banking institutions. As previously stated, distributed ledger technology is behind the Bitcoin platform. Mr. Pavlick acknowledges distributed ledger technology makes the Bitcoin platform possible. However, as Mr. Pavlick observes, banks are not interested in entertaining Bitcoin or any currency lacking a legitimate supportive authority. "The financial services industry has been slow to accept bitcoins and other online currencies, mostly due to questions about stability and security" (PNC Bank, 2016).

Notwithstanding the apparent rejection of Bitcoin, the acknowledgment of the distributed ledger technology by large U.S. based financial institutions draws attention to the importance and future role of algorithms within the U.S. marketplace. Algorithms provide the mathematical programming behind the distributed ledger technology. In addition, it demonstrations the industry's commitment to advancing technology and highlights the transformation of an industry model previously established with the signing of the Federal Reserve Act in 1913.

This paper presents a review of literature to provide an understanding of the transformation of the U.S. Banking Industry created by advancing technology. This paper includes five sections: (1.) Distributed Ledger Technology (2.) Algorithms (3.) Theory of Transformation, (4.) Theory of Transformation Pressure, (5.) Bimodal Transformation. 


\section{Distributed Ledger Technology}

Distributed ledger technology is a settlement technology which according to Dr. Broadbent (2016), Deputy Governor of the London School of Economics and Political Science, "... allows transfers to be verifiably recorded without the need for a trusted third party" ( $3{ }^{\text {rd }}$ paragraph). Hence, as Dr. Broadbent observes, such technology is considered valuable when no third party exists or when such verifications occur on a multilateral basis where the process is costly. Dr. Broadbent describes distributed ledger technology as "...decentralised virtual clearinghouse and asset register" $\left(46^{\text {th }}\right.$ paragraph). Figure 1 depicts a distributed ledger diagram.

\section{Distributed Ledger Taxonomy}

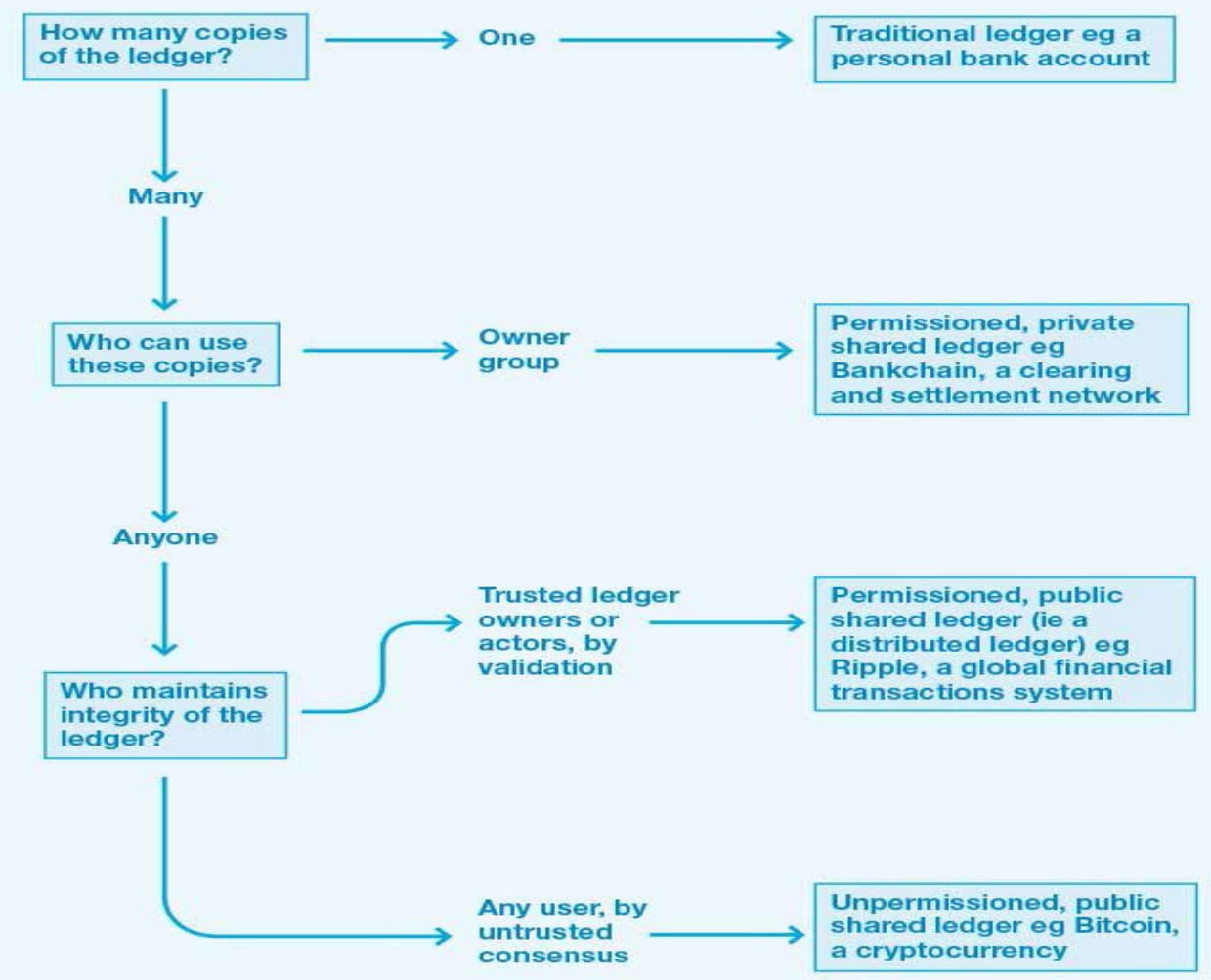

Figure 1. (Hancock \& Vaizey, 2016)

As explained by Hancock and Vaizey (2016), all entities within the distributed ledger system are equipped with identical copies of the ledger. The identical ledgers are then updated simultaneously within seconds of any changes. As security and accuracy of assets are of the utmost importance, "... assets stored in a ledger are maintained cryptographically through the use of 'keys' and signatures to control who can do what within the shared ledger" (Hancock \& Vaizey, 2016, p. 5).

\section{Algorithms}

What is the driving force behind distributed ledger technology? Algorithms. According to Hancock and Vaizey (2016), "Algorithms that enable the creation of distributed ledgers are powerful, disruptive innovations that could 


\section{Issues in Information Systems \\ Volume 17, Issue II, pp. 9-16, 2016}

transform the delivery of public and private services and enhance productivity through a wide range of applications" (p. 5). MacCormick (2012) states that two key conditions are essential for an acceptable algorithm; 1.) each step must be absolutely precise and 2.) it must be devoid of human intuition or guesswork. The connection of algorithms to computers comes into play as computers must be programmed with meticulous instructions (MacCormick, 2012). Therefore, algorithms are a key principle to the study of computer science and according to Lustig and Nardi (2015) are a "...crucial part of software development..."(p. 1). Two examples of algorithms that have influenced, and continue to influence, daily life within the United States are Google's PageRank algorithm and public key cryptography (MacCormick, 2012).

\section{Algorithmic Authority}

Per Lustig and Nardi (2015), algorithmic authority explains the desire of society and organizations to implement algorithms into daily activities, which is evident with the growing interest, by financial institutions, in distributed ledger or blockchain technology. Algorithmic authority, as defined by Lustig and Nardi (2012), “... is the legitimate power of algorithms to direct human action and impact which information is considered true" (p. 1). Based on Lustig and Nardi (2012), humans favor algorithmic authority over the authority of standard institutions such as banks and other various financial institutions. The certainty provided by algorithmic authority is viewed as trustworthy whereas the conventional institution is not (Lustig \& Nardi, 2012).

\section{Algorithms and Banking}

The banking industry continuously gathers and stores data however the data is useless without the ability to quickly utilize it for decision making purposes, hence the importance of the algorithm within the U.S. banking industry (Mihaescu, 2015). Mihaescu (2015) equates a modern and successful company to an 'algorithm company' “....where the core value the company is bringing to the economic ecosystem is a collection of smart algorithms coupled with extensive data collection and real-time actionable results" ( $8^{\text {th }}$ paragraph). So the question is, has big data given way to an algorithmic economy? According to Mr. Sondergaard, SVP at Gartner, a leading information technology research and advisory company headquartered in Stamford, CT, the algorithmic economy is upon us. As Sondergaard sees it, "The algorithmic economy will power the next great leap in machine-to-machine evolution...Products and services will be defined by the sophistication of their algorithms and services. Organizations will be valued, not just on their big data, but the algorithms that turn that data into actions, and ultimately impact customers" ( $6^{\text {th }}$ paragraph).

Not everybody, however, has bought into the current state of an algorithmic economy. Daniel Pavlick, CIO for PNC Corporate \& Institutional Banking, posits that algorithms are "...just the math of the steps". As he sees it, information drives the economy and information is abundant therefore the U.S. is experiencing a 'mixed economy'.

As the sorting and organization of big data has become faster and more reliable with the implementation of algorithms, the question now becomes is the U.S. banking industry experiencing a transformation never before regarded as possible? The Theory of Transformation leads us to believe that the answer is yes.

\section{Theory of Transformation}

According to Daszko and Sheinberg (2005), transformation equates to change but not all change may be viewed as transformational. Not all technology breakthroughs and process enhancements are transformative. Transformation occurs when a new vision leads to the development of a new system or methodology not previously conceived. Daszko and Sheinberg (2005) define transformation as “...the creation and change of a whole new form, function or structure. To transform is to create something new that has never existed before and could not be predicted from the past" (p. 1).

A transformation within an organization or industry requires profound knowledge. As Daszko and Sheinberg (2005) notes, transformation occurs through “...continual questioning, challenging, exploration, discovery, evaluation, 
testing..." (p. 4) and through profound knowledge weaknesses, flaws, and defects become apparent. Therefore, transformation may be viewed as a journey through indeterminate territory.

Table 2 identifies the three types of changes as categorized by Daszko and Sheinberg (2005). Per their definition, one may argue the transformation of the U.S. banking industry is underway with the emergence of advancing technology such as distributed ledger technology as well as the increasing role of algorithms within the U.S. economy.

Table 2. Three Types of Changes

\begin{tabular}{|c|c|c|c|}
\hline Type of Change & Traditional & Transitional & Transformational \\
\hline Motivation for Change & Better, Faster, Cheaper & Fix a Problem & $\begin{array}{l}\text { Survival, Environment, } \\
\text { World Changes, } \\
\text { Breakthrough needed }\end{array}$ \\
\hline Degree of Change & $\begin{array}{c}\text { Incremental } \\
\text { Improvements }\end{array}$ & $\begin{array}{c}\text { Transition from old to } \\
\text { new }\end{array}$ & $\begin{array}{c}\text { Revolutionary, } \\
\text { Necessary }\end{array}$ \\
\hline Thinking & Improve & $\begin{array}{l}\text { Change management; } \\
\text { strategic planning }\end{array}$ & $\begin{array}{c}\text { Radical shifts in } \\
\text { mindset/thinking/actions }\end{array}$ \\
\hline Actions & $\begin{array}{l}\text { Manage and control } \\
\text { processes }\end{array}$ & $\begin{array}{l}\text { Design the plan; } \\
\text { implement the plan }\end{array}$ & $\begin{array}{l}\text { Whole system change, } \\
\text { System of profound } \\
\text { knowledge, paradigms, } \\
\text { culture, } \\
\text { communications, use of } \\
\text { data, structure, systems } \\
\text { and processes }\end{array}$ \\
\hline Destination & $\begin{array}{l}\text { Improvements; can be } \\
\text { limited to improving } \\
\text { the wrong things }\end{array}$ & Projects completed & $\begin{array}{c}\text { Continually } \\
\text { transforming; no end } \\
\text { state }\end{array}$ \\
\hline Change Requires & Improvement of skills & Controlled process & $\begin{array}{l}\text { Committed to new } \\
\text { thinking, learning, and } \\
\text { actions. }\end{array}$ \\
\hline Outcomes & Improvements, limited & Changes, limited & $\begin{array}{c}\text { Sustainable change, new } \\
\text { system: agile, adaptable, } \\
\text { emerging, moving } \\
\text { forward, connected }\end{array}$ \\
\hline
\end{tabular}

The U.S. banking industry is undergoing an evolution created by the continuing advancement of information technology. A radical shift to a new transactional process eliminating the need for an establishment founded in early 1900 's is being explored, evaluated, and tested.

Transformation is not cheap. Daniel Pavolick, CIO for PNC Corporate \& Institutional Banking, acknowledges there is a cost to advancing and implementing technical changes. As previously noted, Digital Asset Holdings collected approximately $\$ 50$ million in investments from 13 U.S. banking entities. What would motivate U.S. banking these financial institutions to invest so much in distributed ledger technology? Applying Erixon and Johannesson's theory of transformation pressure (TTP) the answer may be attributed to the fear of declining profits.

\section{Theory of Transformation Pressure}

According to Erixon and Johannesson (2015), innovation and productivity ensue when a decline in an entity's profits or bottom line income occurs. An economic argument surrounding for profit organizations is that negative shocks increase productivity and rekindle research and development (Erixon \& Johannesson (2015). Per Erixon and Johannesson (2015), the theory of transformation pressure “....maintains that actors become more creative, rational and alert, including the possibility of overreaction, in recessions" (p. 476).

According to Moore (2011), "The Great Recession of 2008-09 witnessed not only the appearance of U.S. banks on the FDIC's 'problem list', or their actual failure, in numbers unseen since the 1930's" (p. 87). Moore (2011) notes 


\section{Issues in Information Systems \\ Volume 17, Issue II, pp. 9-16, 2016}

that prior to the 2008-09 banking crisis U.S. banks had not diversified or enhanced the industry model despite the fact that banking and consumer needs were evolving.

It was during this recession, 2009 to be exact, that the Bitcoin platform supported by distributed ledger technology, otherwise known as blockchain technology, was introduced. The first bitcoin block introduced to the world was known as the Genesis block. Since then the Bitcoin platform along with its distributed ledger technology has gained popularity and notoriety. Fanning (2015) notes the Bitcoin trend is spreading as well-known brick and mortar stores, such as Home Depot, Sears and CVS, have begun accepting the digital currency.

The Bitcoin platform enables consumers to complete a transaction without the need of a "middleman", such as a bank. The Bitcoin algorithm allows consumers to bypass transaction fees imposed by banks and financial institutions as the digital currency is based on the distributed ledger's peer-to-peer system. Consumers' ability to bypass banks' transaction fees threatens a major profit source for the U.S. banking industry. For example, Huang and Dulaney (2015) note that BNY Mellon reported, for the quarter ending June 30, 2015, total fee and other revenue increased $2.9 \%$ to $\$ 3.07$ billion. Similarly, JP Morgan Chase's 2015 Annual Report, indicated approximately $\$ 12.4$ billion in fee income, this includes investment banking fees and lending and deposit related fees. Chase reported approximately $\$ 93.5$ billion in net income for year-ending December 30, 2015 of which approximately $\$ 12.4$ billion or $13 \%$ was fee income.

U.S. banks pressure to explore, examine, and understand the distributed ledger technology appears to be in the industry's best interest for the lack of understanding the advancing technology may interfere with a revenue stream essential to the industry.

\section{Bimodal Transformation}

The U.S. banking industry has entered uncertain territory through the exploration of distributed ledger technology while maintaining and adhering to traditional banking policies and procedures (Mode 1). Since the establishment of the Federal Reserve System during 1913-1914, U.S. banks have operated under the central bank's authority for over 100 years. Gartner (2015), a leading information technology research and advisory company, refer to an organization's legacy systems as Mode 1. Per Gartner's (2015) conceptual model, Mode 2 refers to an entity's platform which utilizes "...more cloud than in-house infrastructure and applications. Per Mr. Sondergaard, SVP at Gartner, organizations " .... are trying new ways of reaching the customer, of running operations, of driving diverse innovation. They are acquiring and investing in digital technology companies..." (Gartner, 2015, 10 $0^{\text {th }}$ paragraph). Per Mr. Sondergaard, Mode 2 focuses less on the gathering of data and more on the development of intelligent algorithms to interpret the data. Mr. Sondergaard states organizations must be bimodal to achieve success. Put simply, U.S. banks must adopt a bimodal operational platform to remain competitive within the U.S. marketplace. Table 3 identifies the two necessary banking modes.

Table 3

\begin{tabular}{|c|c|}
\hline Mode 1 & $\begin{array}{c}\text { Consisting of banks legacy system. } \\
\text { Maintaining role of middleman. }\end{array}$ \\
\hline Mode 2 & $\begin{array}{c}\text { Incorporating advancing technology } \\
\text { such as distributed ledger } \\
\text { technology. }\end{array}$ \\
\hline
\end{tabular}

The testing and examination of distributed ledger technology, also known as blockchain technology, which is considered Mode 2, challenges the current status quo of U.S. banking legacy systems or Mode 1. Figure 3 depicts the process of bank transactions under the Federal Reserve System (central authority) versus the implementation of distributed ledger technology. 


\section{Issues in Information Systems \\ Volume 17, Issue II, pp. 9-16, 2016}

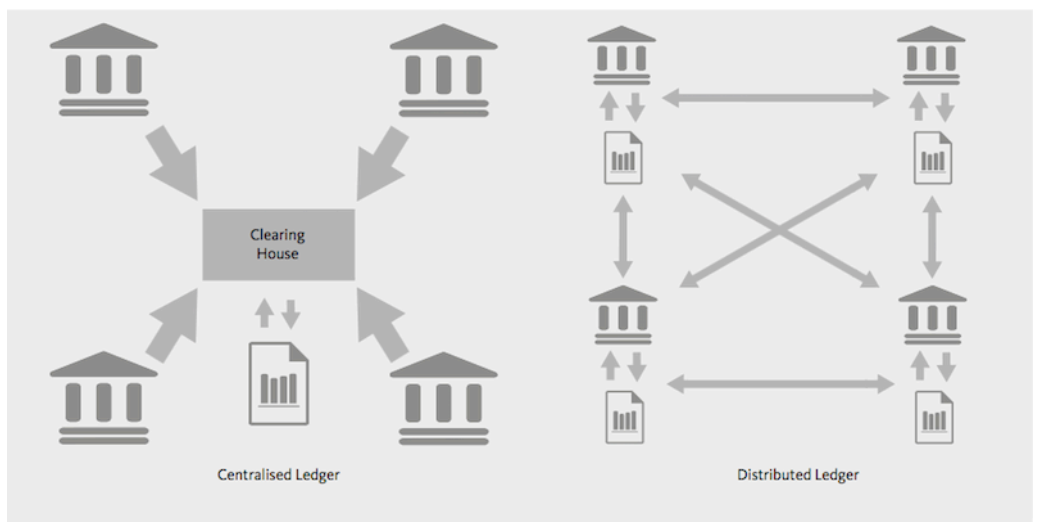

Figure 2

Per Daniel Pavlick, CIO for PNC's Corporate \& Institutional Banking, a bimodal transformation to encompass distributed ledger infrastructure "...offers distributed information transparency and verification that could lead to increased efficiency and risk reduction..." (PNC Bank, 2016). In addition, Mr. Pavlick adds that distributed ledger technology represents ".... a disruptive technology that will force all industry participants to rethink how they approach new product and service development” (PNC Bank, 2016).

\section{CONCLUSION}

In conclusion, the transformation of the U.S. banking industry is underway as evidenced by the investment in Digital Asset Holdings LLC by some 13 leading financial institutions. Failure to transform poses risks to bottom-line profits and industry significance. As stated by Christopher Ward, PNC's product management head for Treasury Management, the potential applications of distributed ledger technology “.... are widespread both in making existing products more efficient and more transparent, but also by providing the ability to revolutionize how some segments transact business with each other" (PNC Bank, 2016).

As depicted, bimodal transformation has never before been undertaken within the U.S. banking industry. When, not if, there is an attempt to introduce this new technology the role of the Federal Reserve, the current central authority and existing regulatory policies remain uncertain. The question of how the distributed ledger technology will affect business and banking relationships within the U.S. marketplace remains open for future research.

\section{REFERENCES}

Brainard, L. (2016, April 14). The use of distributed ledger technologies in payment, clearing and settlement. Board of Governors of the Federal Reserve System at institute of international finance blockchain roundtable. Washington, D.C. Retrieved July 5, 2016 from https://www.federalreserve.gov/newsevents/speech/brainard20160414a.pdf

Daszko, M. \& Sheinberg, S. (2005, April). Survival is optional: Only leaders with new knowledge can lead the transformation. Transformation, 408, 247-7757.

Erixon, L. \& Johannesson, L. (2015). Is the psychology of high profits detrimental to industrial renewal? experimental evidence for the theory of transformation pressure. Journal of evolutionary economics, $25(2), 475-511$. 


\section{Issues in Information Systems}

Volume 17, Issue II, pp. 9-16, 2016

Gartner. (2015, October 5). Gartner sys it's not just about big data; It's what you do with it: Welcome to the algorithmic.

Geuss, M. (2016, April 8). In recent test, blockchain brings transparency to notorious credit default swaps. ars technical. Retrieved June 30, 2016, from http://arstechnica.com/information-technology Economy. Retrieved from http://www.gartner.com/newsroom/id/3142917

Huang, D. \& Dulaney, C. (2015, July 21). BNY Mellon profits surge 48\%; Suit settlements, fee and foreignexchange revenue growth help bank's bottom line. The Wall Street Journal. Retrieved from ProQuest database.

Lustig, C. \& Nardi, B. (2015, January). Algorithmic Authority: The case of Bitcoin. In System Sciences (HICSS), $201548^{\text {th }}$ Hawaii International Conference, pp. 743-752. IEEE.

MacCormick, J. (2012) Nine algorithms that changed the future: The ingenious ideas that drive today's computers. Princeton University Press.

Mihaescu, M. (2015, April 22). The new age of algorithms. Retrieved from http://banknxt.com/49972/new-age-of-algorithms/

Moore, J. (2011). Bank performance prediction during the 'Great Recession' of 2008-09: A pattern-recognition approach. Academy of Banking Studies Journal, 10(2), 87-104.

PNC Bank. (2016, January 21). PNC makes equity investment in Digital Asset Holdings. Retrieved March 30, 2016, from http://intranet.pnc.com

PNC Bank. (2016, February 3). PNC Primer: Blockchain, simplified! Retrieved March 30, 2016, from http://intranet.pnc.com 